
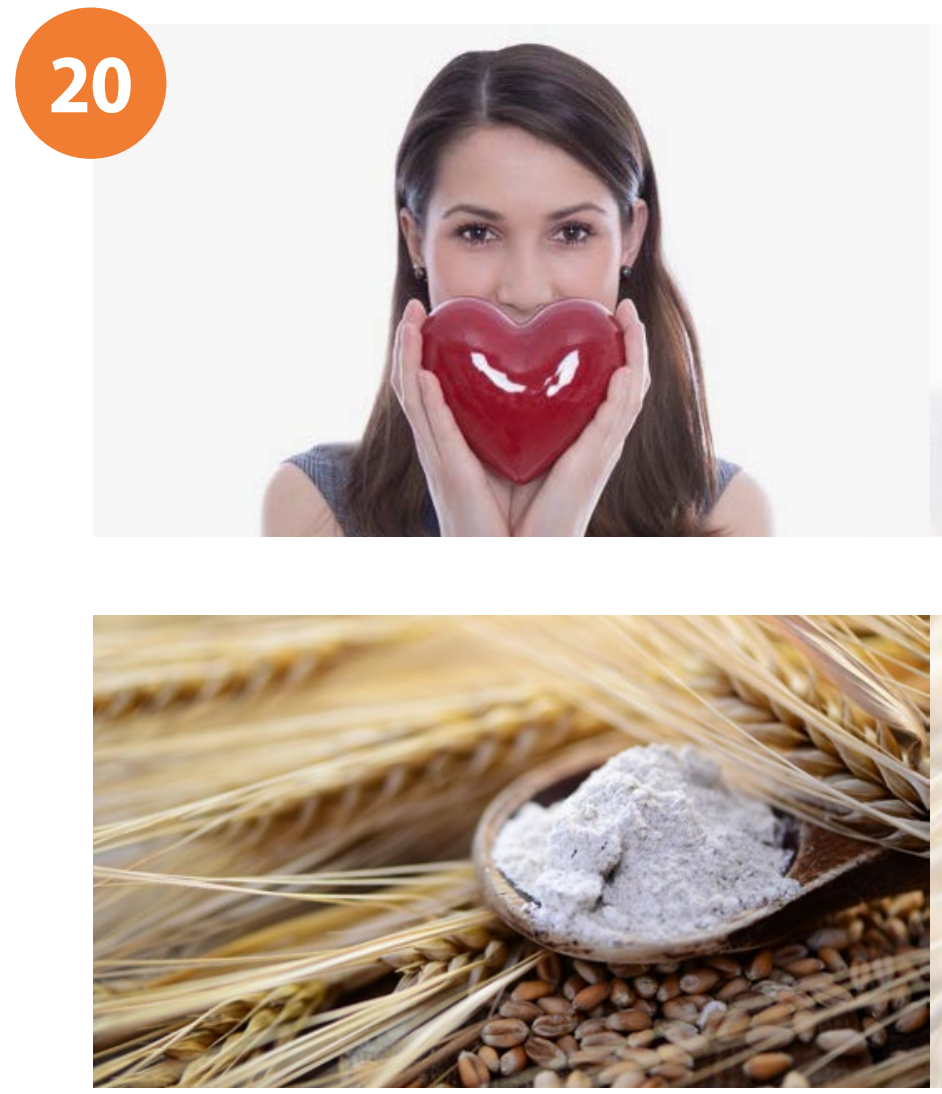

Medizin

6 Laser kann Therapie von Nagelpilz unterstützen

7 Diabetesrisiko steigt auch bei normalen Zuckerwerten

18 Tipps für Reisen mit Asthma und COPD

19 Blickdiagnose: Hautveränderungen kamen über Nacht

29 GOÄ oder EBM? Das ist bei

erektiler Dysfunktion die Frage!

33 So stehen die Chancen für extreme Frühchen

40 Crohn und Colitis: Hoffnung auf neue Therapieoptionen

44 COPD-Leitlinien vor Änderung

\section{Schwerpunkt Kardiologie}

20 Medikamentöse Therapie der stabilen KHK

22 Noch tieferes LDL ist noch besser!

24 Prävention durch DOAK bei geriatrischen Patienten

26 Score zur Frühdiagnostik der Herzinsuffizienz

\section{CME Fortbildung}

9 Häufige Kopfschmerzerkrankungen Von Migräne bis Clusterkopfschmerz

51 Zöliakie - Das Chamäleon der Gastroenterologie Praktische Tipps zu Diagnose und Therapie

\section{Notfallmedizin}

28 „Time is brain“ - nur das zählt bei der Rettung Ertrinkender

Rechtsmedizin

30 Die Persönlichkeit von Attentätern

Hautecke

32 Hyperhidrose: Nasse Stellen trocken legen

Schmerz

34 Noch keine "Opioid-Epidemie" in Deutschland
Hier steht eine Anzeige.

$$
\text { Springer }
$$

Der prominente Patient

36 Friedrich III: Erst heiser, dann endgültig verstummt

Arzt und Recht

50 Was Ärzte Versicherern sagen dürfen

Rubriken

46 Therapie aktuell

59 Impressum/Cartoon 